Article

\title{
Evaluation of the Potential of Biofilm Formation of Bifidobacterium longum subsp. infantis and Lactobacillus reuteri as Competitive Biocontrol Agents Against Pathogenic and Food Spoilage Bacteria
}

\author{
Barbara Speranza ${ }^{1}$, Arcangelo Liso ${ }^{2, *(\mathbb{D})}$, Vincenzo Russo ${ }^{3}$ and Maria Rosaria Corbo ${ }^{1, *(D)}$ \\ 1 Department of the Science of Agriculture, Food and Environment (SAFE), University of Foggia, \\ Via Napoli 25, 71122 Foggia, Italy; barbara.speranza@unifg.it \\ 2 Department of Medicine and Surgery, University of Foggia, Polo Biomedico, Viale Pinto 1, 71122 Foggia, Italy \\ 3 Institute of Ophthalmology, Department of Surgery Science, University of Foggia, Viale Pinto, 71122 Foggia, \\ Italy; virus66@alice.it \\ * Correspondence: arcangelo.liso@unifg.it (A.L.); mariarosaria.corbo@unifg.it (M.R.C.)
}

Received: 29 November 2019; Accepted: 21 January 2020; Published: 25 January 2020

check for updates

\begin{abstract}
This study proposes to exploit the in vivo metabolism of two probiotics (Bifidobacterium longum subsp. infantis and Lactobacillus reuteri) which, upon adhesion on a solid surface, form a biofilm able to control the growth of pathogenic and food spoilage bacteria. The results showed that pathogenic cell loads were always lower in presence of biofilm $\left(6.5-7 \mathrm{log} \mathrm{CFU} / \mathrm{cm}^{2}\right)$ compared to those observed in its absence. For Escherichia coli O157:H7, a significant decrease (>1-2 logarithmic cycles) was recorded; for Listeria monocytogenes, Staphylococcus aureus, and Salmonella enterica, cell load reductions ranged from 0.5 to 1.5 logarithmic cycles. When tested as active packaging, the biofilm was successfully formed on polypropylene, polyvinyl chloride, greaseproof paper, polyethylene and ceramic; the sessile cellular load ranged from $5.77 \log \mathrm{CFU} / \mathrm{cm}^{2}$ (grease-proof paper) to $6.94 \mathrm{log}$ $\mathrm{CFU} / \mathrm{cm}^{2}$ (polyethylene, $\mathrm{PE}$ ). To test the potential for controlling the growth of spoilage microorganisms in food, soft cheeses were produced, inoculated with L. monocytogenes and Pseudomonas fluorescens, wrapped in PE pellicles with pre-formed biofim, packed both in air and under vacuum, and stored at 4 and $15{ }^{\circ} \mathrm{C}$ : an effective effect of biofilms in slowing the decay of the microbiological quality was recorded.
\end{abstract}

Keywords: probiotic; biofilm; pathogen; spoilage bacteria; active packaging

\section{Introduction}

Despite that their use in foods is dated, in the last decades, Lactic Acid Bacteria (LAB) have attracted much attention for their documented beneficial properties and for potential useful applications. Among LAB, several strains are currently claimed as probiotics [1], i.e., live microorganisms that, when administered in adequate amounts, confer a health benefit on the host [2]. According to the consensus statement, there are some bacterial species with a long history of safe use and a well-recognized health effect, such as Bifidobacterium adolescentis, B. animalis, B. bifidum, B. breve, B. longum, Lactobacillus acidophilus, L. reuteri, L. casei, L. fermentum, L. gasseri, etc. [2]; some strains, such as B. longum subsp. infantis and L. reuteri, are widespread due to the strong evidence of their effect on health [3]. Probiotics are able to colonize, stably or transiently, host mucosal surfaces, including the gut, where they may contribute to host health; the capacity of probiotics to colonize biotic and abiotic surfaces by forming structured communities (i.e., biofilms), could have great potentials for human 
health and food safety biotechnologies, although this aspect has is in fact barely been explored. It has recently been shown that microbial biofilms may play several "useful" roles such as biodegradation of toxic compounds and pollutants, bioremediation, toxic effluents treatment [4], despite being initially considered only a negative phenomenon. These applications suggest that microbial biofilms could be successfully used for new applications in the biomedical, industrial, food, and environmental field [4].

In the biomedical field, for example, a biofilm formed by probiotic microorganisms could be potentially useful to hinder the development of microorganisms responsible for infections, especially those caused by microorganisms of hospitals, typically resistant to common antibiotic treatments. Indeed, it is widely accepted that in the development of direct and airborne transmission of nosocomial infections, the hospital environment (infection reservoir) plays a key role [5]. In fact, it can be anticipated that a probiotic biofilm left to form ad hoc on several surfaces (e.g., toilets, air conditioning systems) could reduce the spread of pathogenic species that may harbor thereon. Other potential applications in the biomedical field could be: preparations used in skin lesions for the healing processes to add antibacterial capacity, the coating of implants and catheters, medical devices applied to the oral cavity which might hinder the growth of bacterial species associated with caries and periodontal disease [6-9].

On the other hand, regarding potential applications in the food industry, biofilms can be used to ensure the hygienic-sanitary safety of food products, as well as an extension of their shelf-life. The formation of biofilms by "useful/probiotic" microorganisms may be stimulated on materials commonly used to package food (plastic films, pellicles, combinations for packaging, paper, etc.) in order to develop an innovative active packaging system. Although the scientific community is very active in the production of research related to the ability of microorganisms to form biofilms, most studies have focused on biofilm formation by pathogens and/or spoilage microorganisms (Enterobacter, Listeria, Micrococcus, Streptococcus, Bacillus and Pseudomonas) [10-13]. It has been also shown that certain species of LAB are able to form biofilms and some of them are capable of exhibiting antimicrobial activity against pathogenic microorganisms [14-16]; some research was conducted on the possibility of using new methods of sanitation, exploiting the principle of biological competition using probiotic products [17], but this aspect needs to be explored further. In a previous study, we have described the optimization of the production of a probiotic biofilm through intermediate steps by fixing some valuable key points about the probiotics' ability to adhere to surfaces and to form biofilms [18]. These results were used to file a patent covering the use of probiotic biofilms as a means to control pathogen growth [19]. Even if some studies in literature present the use of LAB (mainly lactobacilli) biofilms to control pathogen growth in food and superficies [20-27], most of them propose the use of bio-surfactants and compounds with antimicrobial activity produced in greater quantities by lactobacilli when growing in sessile form. Indeed, our study proposes a probiotic biofilm that exploits the in vivo metabolism of two selected probiotic strains able to adhere rapidly on abiotic surfaces, and not the substances secreted by them and subsequently recovered and used, as in the prior art. To the best of our knowledge, only one study has previously proposed a similar approach evaluating the use of potential probiotic LAB (isolated from Brazilian's foods) biofilms to control Listeria monocytogenes, Salmonella Typhimurium, and Escherichia coli O157:H7 biofilms formation and suggesting that LAB strains can be excellent candidates to form protective biofilms to be used as biocontroller of contamination into the food chain [28].

Besides the use as an innovative active packaging to ensure the safety of food products, as well as an extension of their shelf-life, the proposed probiotic biofilm formed ad hoc on medical devices (catheters, implants, braces, bite blocks or condoms) and on bathrooms' surfaces (sink, bidet, toilet bowl, water closet or piece of furniture) could be considered a tool against colonizing strains, since these surfaces are often implicated in nosocomial infections. Our proposal could lead to the development of a useful means to control the growth of pathogenic and spoilage bacteria for industrial and medical applications. In the following, some specific applications of the developed probiotic biofilm are described, focusing on two different aspects: 1) effect of probiotic biofilms on pathogen sessile growth; 2) application as potential active packaging. 


\section{Materials and Methods}

\subsection{Effect of Probiotic Biofilms on Pathogen Sessile Growth}

\subsubsection{Surfaces and Microorganisms}

Polycarbonate resin (Lexan, Fedele s.r.l., Rome, Italy) was the surface chosen for the adhesion experiments. Before each experiment, the chips $(2.5 \times 5.0 \times 0.05 \mathrm{~cm})$ were prepared by washing in acetone for a minimum of $30 \mathrm{~min}$, rinsing in distilled water, and then soaking in $1 \mathrm{~N} \mathrm{NaOH}$ for $1 \mathrm{~h}$. After a final rinse in distilled water, the chips were allowed to air dry. This cleansing procedure was required to remove fingerprints, oils grease, and other soils that may have been on the materials. The cleaned chips were finally autoclaved at $121^{\circ} \mathrm{C}$ for $15 \mathrm{~min}$ prior to use.

The probiotic strains used for this study were Bifidobacterium longum subsp. infantis DSM20088 and Lactobacillus reuteri DSM20016, both purchased from Leibniz-Institut DSMZ (Deutsche Sammlung von Mikroorganismen und Zellkulturen) and stored at $-20{ }^{\circ} \mathrm{C}$ in MRS broth (Oxoid, Milan, Italy).

Before each assay, they were grown in their optimal media at their optimal conditions, until late exponential phase was attained; namely, MRS broth added with cysteine $0.05 \%$ (w/v) (Sigma-Aldrich, Milan, Italy) incubated at $37^{\circ} \mathrm{C}$ for 24 to $48 \mathrm{~h}$, under anaerobic conditions, and MRS broth (Oxoid) incubated at $30{ }^{\circ} \mathrm{C}$ for 24 to $48 \mathrm{~h}$, under anaerobic conditions, were used for B. infantis DSM20088 and L. reuteri DSM20016, respectively.

Cells cultures were successively harvested by centrifugation for $10 \mathrm{~min}$ at $4500 \mathrm{rpm}\left(4^{\circ} \mathrm{C}\right)$ and the pellets were washed twice with sterile saline solution $(0.9 \% \mathrm{NaCl})$ at $4{ }^{\circ} \mathrm{C}$ and finally resuspended in the same solution at a cell concentration of $1 \times 10^{8} \mathrm{CFU} / \mathrm{mL}$.

As pathogen targets were chosen, four strains belonging to the Culture Collection of the Laboratory of Predictive Microbiology (Department of the Science of Agriculture, Food and Environment, Foggia University), and microorganisms with the media and growth conditions used, have been listed in Table 1. The organisms were transferred to fresh Nutrient Agar (NA, Oxoid) periodically to maintain viability and, prior to use, they were activated by two successive 24-h transfers of cells in Nutrient broth (NB, Oxoid) at $37^{\circ} \mathrm{C}$. Inocula for experiments were prepared by centrifugation of the 24-h microbial cultures at $3000 \times \mathrm{g}$ for $15 \mathrm{~min}$ at $4^{\circ} \mathrm{C}$. After centrifugation, the obtained pellets were resuspended in sterile saline solution at $4{ }^{\circ} \mathrm{C}$ to obtain approximately $10^{8} \mathrm{CFU} / \mathrm{mL}$ for each microorganism.

Table 1. Pathogen strains used in the study with the indication of their source and optimal media and growth conditions adopted.

\begin{tabular}{|c|c|c|}
\hline Strains & Source & $\begin{array}{l}\text { Optimal Media and Growth } \\
\text { Conditions }\end{array}$ \\
\hline Listeria monocytogenes * & $\begin{array}{c}\text { Culture Collection of the Laboratory of } \\
\text { Predictive Microbiology, SAFE, } \\
\text { University of Foggia }\end{array}$ & $\begin{array}{l}\text { Listeria selective agar base (Oxoid) plus } \\
\text { Listeria selective supplement-Oxoid } \\
\text { formulation, incubated at } 37^{\circ} \mathrm{C} \text { for } 48 \mathrm{~h}\end{array}$ \\
\hline Escherichia coli O157:H7 & CECT 4267 & $\begin{array}{l}\text { Sorbitol MacConkey Agar (Oxoid), } \\
\text { incubated at } 37^{\circ} \mathrm{C} \text { for } 24 \mathrm{~h}\end{array}$ \\
\hline Staphylococcus aureus & ATCC 25923 & $\begin{array}{c}\text { Baird-Parker Agar Base (Oxoid) plus } \\
\text { Egg Yolk Tellurite Emulsion, incubated } \\
\text { at } 37^{\circ} \mathrm{C} \text { for } 24 \mathrm{~h}\end{array}$ \\
\hline Salmonella enterica & ATCC 35664 & $\begin{array}{c}\text { Chromatic Salmonella Agar (Liofilchem, } \\
\text { Roseto degli Abruzzi, Teramo, Italy), } \\
\text { incubated at } 37^{\circ} \mathrm{C} \text { for } 24 \mathrm{~h}\end{array}$ \\
\hline
\end{tabular}

\subsubsection{Experiment}

Biofilm formation was favoured by simultaneously inoculating the cocktail of identified probiotics (B. infantis DSM20088 and L. reuteri DSM20016, about $\sim 10^{8} \mathrm{CFU} / \mathrm{mL}$ ) and the pathogenic target $\left(\sim 10^{7} \mathrm{CFU} / \mathrm{mL}\right)$ on polycarbonate surfaces (Lexan ${ }^{\circledR}$ tiles, $25 \mathrm{~mm} \times 75 \mathrm{~mm}, 0.5 \mathrm{~mm}$ thick) left at 
room temperature $\left(20^{\circ} \mathrm{C}\right)$ for $2 \mathrm{~h}$. After this time interval, the tiles were transferred to aliquots of peptone water ( $1 \%$ bacteriological peptone) and incubated at $15^{\circ} \mathrm{C}$ for $48 \mathrm{~h}[18,19]$. Specifically, for each pathogen, two samples were prepared: an ACTIVE sample (ACT), containing a chip where probiotics were left to form biofilm; a CONTROL sample (CNT), containing a chip without probiotics. The pathogen sessile cell load was determined after $0,4,24,30$ and $48 \mathrm{~h}$ after inoculation. At these times, chips were aseptically removed and rinsed with sterile distilled water, in order to eliminate the unattached cells. As suggested in literature [29], sessile cells were detached from chips in a sterile test tube containing $45 \mathrm{~mL}$ of sterile saline with a $20 \mathrm{~Hz}$ "Vibra Cell" sonicator (SONICS, Newcastle, Conn., USA) for $3 \mathrm{~min}$. Viable and cultivable cells were enumerated by serial dilutions in $0.9 \% \mathrm{NaCl}$ solution and plating on appropriate media (Table 1).

\subsection{Application as Potential Active Packaging}

\subsubsection{Probiotic Biofilm Formation on Different Materials}

The materials assayed were polypropylene (PP), polyvinyl chloride (PVC), greaseproof paper (GP), waxed paper (WP), polyethylene (PE) and ceramic; all materials were cut in rectangles of $2.5 \times 5.0 \mathrm{~cm}$ and cleaned by immersion in ethanol. Each individual chip was well rinsed with ultrapure water and dried at room temperature. Probiotic biofilms were left to form for $96 \mathrm{~h}$ by simultaneously inoculating the cocktail of probiotics (B. infantis DSM20088 and L. reuteri DSM20016, about $\sim 10^{8} \mathrm{CFU} / \mathrm{mL}$ ) on chips of different materials, left at room temperature $\left(20^{\circ} \mathrm{C}\right)$ for $2 \mathrm{~h}$. After this time interval, the chips were transferred to aliquots of peptone water ( $1 \%$ bacteriological peptone) and incubated at $15^{\circ} \mathrm{C}$ for $96 \mathrm{~h}$ [19].

Biofilm cells were enumerated at 2, 24, and $96 \mathrm{~h}$ after inoculation. At these times, chips were aseptically removed and rinsed with sterile distilled water, in order to eliminate the unattached cells. Sessile cells were detached from chips in a sterile test tube containing $45 \mathrm{~mL}$ of sterile saline with a "Vibra Cell" sonicator (SONICS, Newcastle, Conn., USA) at $20 \mathrm{kHz}$ for $3 \mathrm{~min}$. Viable and cultivable cells were enumerated by serial dilutions in $0.9 \% \mathrm{NaCl}$ solution and plating on MRS Agar (Oxoid).

\subsubsection{Challenge Tests}

Inoculations for experiments were prepared by centrifugation of the 24-h microbial cultures in an ALC 4239R centrifuge (ALC, Milan, Italy) at $3000 \times \mathrm{g}$ for $15 \mathrm{~min}$ at $4{ }^{\circ} \mathrm{C}$. For the inoculations of challenge tests, after centrifugation the pellets were resuspended in sterile isotonic solution $(0.9 \%$ $\mathrm{NaCl}$ ) at a temperature of $4{ }^{\circ} \mathrm{C}$ and serial dilutions were made to obtain approximately $10^{4} \mathrm{CFU} / \mathrm{mL}$ for each microorganism. For biofilm formation, the probiotic pellet was resuspended in sterile isotonic solution at a temperature of $4{ }^{\circ} \mathrm{C}$ and used on polyethylene films to form experimental pellicles with pre-formed probiotic biofilm (EXP).

Miniature soft cheeses were made using pasteurized, whole and homogenized milk, purchased in a local market. The milk had the following characteristics: lactose $5.0 \%$, protein $3.2 \%$, fat $3.6 \%$, $\mathrm{pH}$ 6.6. The cheeses were produced using a domestic cheese-maker ("Casaro", Philips, Milan, Italy) by pouring the milk into the single-wall cheese-maker vessel and heating to $85^{\circ} \mathrm{C}$. As soon as the temperature reached $85^{\circ} \mathrm{C}$ (after a few minutes), $4 \mathrm{~g} / \mathrm{L}$ of sodium chloride was added and the salted milk was immediately left to cool to $30^{\circ} \mathrm{C}$. Renneting was performed with $3 \mathrm{~mL} / \mathrm{L}$ of liquid calf rennet (concentrate extract of Liquid Rennet, CHR. Hansen s.p.a., Milan, Italy). After coagulation and curd strengthening (approximately $40 \mathrm{~min}$ ), the curd was cut and the whey discarded. Finally, miniature soft cheeses of a round shape ( $25 \mathrm{~g}, 6 \mathrm{~cm}$ diameter) and regular smooth surfaces were made by hand and placed in sterile boxes fitted with a grid to facilitate whey draining. The boxes were kept at room temperature for $6 \mathrm{~h}$ until packaging.

To test the potential for probiotic biofilms to control the growth of microorganisms in soft cheese, they were inoculated with L. monocytogenes (challenge test A) and Ps. fluorescens (challenge test B). The inoculation (about $10^{2} \mathrm{CFU} / \mathrm{g}$ ) was carried out in the most homogeneous way possible, spreading $0.2 \mathrm{~mL}$ of the prepared microbial suspension across the entire surface of miniature cheese by means of a 
sterile spatula. After inoculation, all cheeses were wrapped in polyethylene films (EXP) and packed in high-barrier plastic bags (Nylon/Polyethylene, $102 \mu \mathrm{m}$ (Tecnovac, San Paolo D'Argon, Bergamo, Italy)) by means of S100-Tecnovac equipment. Control batches were prepared by wrapping cheeses in pellicles without pre-formed biofilm (CNT). All samples were packaged in air and under vacuum. During the storage at 4 and $15^{\circ} \mathrm{C}$ for 28 and 14 days, respectively, microbiological analyses, determination of $\mathrm{pH}$ and measurements of $a_{w}$ were made, details of which are given below.

\subsubsection{Microbiological, Chemico-Physical and Sensorial Analyses}

For microbiological analyses, mini-cheeses $(25 \mathrm{~g})$ were diluted with $225 \mathrm{~mL}$ of $0.1 \%$ peptone water with salt $(0.9 \% \mathrm{NaCl})$ in a Stomacher bag (Seward, London, England) and homogenized for $1 \mathrm{~min}$ in a Stomacher Lab Blender 400 (Seward). Serial dilutions of cheese homogenates were plated on the surface of the appropriate media in Petri dishes. The media and the conditions used were: Listeria selective agar base (Oxoid) plus Listeria selective supplement-Oxoid formulation, incubated at $37^{\circ} \mathrm{C}$ for 48 h, for L. monocytogenes; Pseudomonas Agar Base (Oxoid) plus Pseudomonas CFC Supplement, incubated at $25^{\circ} \mathrm{C}$ for $48 \mathrm{~h}$, for Ps. fluorescens; MRS agar (Oxoid), incubated at $30^{\circ} \mathrm{C}$ for 4 days under anaerobiosis, for mesophilic lactobacilli.

For each batch, the measurement of $\mathrm{pH}$ was performed twice on the first homogenized dilution of the cheese samples during storage with a Crison $\mathrm{pH}$ meter model micro pH 2001 (Crison). $a_{w}$ was measured by a hygrometer AQUALAB CX-2 (Decagon Device, Pullman, WA, USA).

During the storage at 4 and $15^{\circ} \mathrm{C}$, a sensory evaluation was also performed: the panel consisted of 15 panelists aged between 22 and 38 years (students and researchers of the Department of the Science of Agriculture, Food and Environment (SAFE), University of Foggia). Using a scale ranging from 0 to 10 (where 10 stands for the most attractive attributes and 0 for the absolutely unpleasant attributes), the sensorial overall quality of the samples was determined by evaluating colour, odour, texture and overall acceptability. During the test sessions, cheese samples were coded by a letter and presented individually to each panelist in plastic cups covered with a lid in random order. Sensory evaluation was conducted in individual booths under controlled conditions of light (white light), temperature $\left(20 \pm 2{ }^{\circ} \mathrm{C}\right)$, and humidity $(70 \%$ to $85 \%)$.

\subsubsection{Statistical Analyses}

All experiments were performed twice with the analyses conducted twice.

Results about the effect of probiotic biofilms on pathogen sessile growth were expressed as log $\mathrm{CFU} / \mathrm{cm}^{2}$, presented as the average of replicates $(n=4)$ and analyzed through the Student's t-test $(p<0.05)$.

To highlight the effectiveness of probiotic biofilm, for each time of analysis the pathogen sessile data were expressed as follows:

\section{Biofilm Efficacy $=\mathrm{CNT}-\mathrm{ACT}$}

where CNT and ACT were pathogen cell numbers $\left(\log \mathrm{CFU} / \mathrm{cm}^{2}\right.$ ) in the control (without probiotic biofilm) and in the active sample (with probiotic biofilm). These differences were analysed through one-way ANOVA and Tukey's test as the post-hoc comparison test $(p<0.05)$. Results about biofilm formation on different materials were expressed as $\log \mathrm{CFU} / \mathrm{cm}^{2}$, presented as the average of replicates $(n=4)$ and analyzed through one-way ANOVA and Tukey's test as the post-hoc comparison test $(p<0.05)$.

The microbiological data collected during the challenge tests were expressed as the average of two replicates and the obtained mean values (one for experiment) were modelled according to the Gompertz equation modified by Zwietering et al. [30]:

$$
y=k+A * \exp \left\{-\exp \left[\left(\mu_{\max } * e / A\right) *(\lambda-t)+1\right]\right\},
$$


where $y$ is the concentration of the microorganism (Log CFU/g), $k$ is the initial level of the dependent variable to be modelled, $A$ is the difference between the decimal logarithm of the initial value of cell concentration and the decimal logarithm of maximum bacteria growth attained at the stationary phase $(\log C F U / g), \mu_{m a x}$ is the maximal growth rate (1/day), $\lambda$ the lag time (day) and $t$ the time.

Following Castillejo Rodriguez et al. [31], the sanitary risk time for the growth of L. monocytogenes in our samples was determined as the time (in days) that it took to observe an increase of $2 \mathrm{Log}$ CFU/g of the count of this microorganism in food as follow:

$$
\text { sanitary risk time }[S R T]=2 / \mu \text {, }
$$

where $\mu$ is the maximal growth rate.

For the growth of Ps. fluorescens, the maximum acceleration of microbial growth $\left(\mathrm{dy}^{2} / \mathrm{dt}^{2}(\mathrm{day})\right)$, known as stability time, was also estimated with the Gompertz equation, following Riva et al. [32].

To determine whether significant differences $(p<0.05)$ existed among the parameters calculated by using the Gompertz equation, a one-way analysis of variance (ANOVA), followed by Tukey's test, was conducted.

Modeling was performed through the software Statistica for Windows version 10.0 (Statsoft, Tulsa, OK, USA).

\section{Results and Discussion}

\subsection{Effect of Probiotic Biofilms on Pathogen Sessile Growth}

In order to evaluate the effect of probiotic biofilms on the development of pathogenic microorganisms, evidence was provided on the growth in sessile form of L. monocytogenes, E. coli O157:H7, St. aureus and S. enterica. Table 2 shows the cellular loads in sessile form relating to the targets studied; the data analysis shows how the pathogens studied were able to develop in all samples, even if they exhibited a wide range in their ability to colonize the surface, with the highest initial adhesion recovered for S. enterica (about $6 \log C F U / \mathrm{cm}^{2}$ ) against the lowest one (about 4 log $\mathrm{CFU} / \mathrm{cm}^{2}$ ) recovered for L. monocytogenes. However, cellular loads were always lower in ACT samples (presence of probiotic biofilm, about 6.5-7 $\log \mathrm{CFU} / \mathrm{cm}^{2}$ ) compared to the CNT samples (absence of probiotic biofilm), highlighting that the studied biofilm was able to control the growth of all inoculated pathogenic targets. To quantify the effectiveness of probiotic biofilms in slowing down the pathogens' adhesion, for each time of analysis the difference between the cellular loads recovered in CNT and ACT samples was calculated. As it can be inferred from Table 2, for E. coli O157:H7, there was a significant decrease in cell load compared to control of more than 1 and 2 logarithmic cycles after 4 and $48 \mathrm{~h}$ of incubation, respectively, and the biofilm efficacy increased over time. Similar results were observed for St. aureus. On the contrary, for L. monocytogenes the effectiveness of probiotic biofilm was maximum after $4 \mathrm{~h}(1.43 \pm 0.28)$, but it decreased over time; this loss of efficacy was also recorded for S. enterica, with cell load reductions ranging from 1 to 0.2 logarithmic cycles after 24 and $48 \mathrm{~h}$, respectively. As expected, biofilms were odorless and invisible to the naked eye. The idea to use probiotics into the prevention of infections and other diseases has already been proposed [7], and is also stimulated by the need of new alternative intervention strategies to combat bacteria pathogenesis due to the increasing evidence of antibiotics resistance of many pathogens. Abdelhamid et al. [33] observed that cell-free preparations of different probiotics belonging to Lactobacillus and Bifidobacterium species were able to reduce the growth of E. coli, whereas Kaboosi [34] showed that probiotics from yogurts had antibacterial effects against Gram negative bacteria such as E. coli, Salmonella Typhi and Ps. aeruginosa, and Gram positive bacteria such as S. aureus. Similarly, Tejero-Sariñena et al. [35] found that 15 strains of probiotics had antibacterial properties against gram negative Salmonella Typhimurium and Clostridium difficile. However, most of these studies propose the use of compounds (mainly bio-surfactants) with antimicrobial activity produced by probiotics, and contained in their cell-free supernatants [20-27]; on the contrary, this study proposes the use of a probiotic biofilm that exploits 
the in vivo metabolism of two bacterial strains (Lactobacillus and Bifidobacterium) adhering on abiotic surfaces and not the substances secreted by probiotics and subsequently recovered and used. In 2014 Schobitz et al. [36] proposed a biocontroller consisting of the thermally treated fermentate (TTF) from two Carnobacterium maltaromaticum strains (ATCC PTA 9380 and ATCC PTA 9381), a strain of Enterococcus mundtii (ATCC PTA 9382), plus nisin at a concentration of $1000 \mathrm{IU} / \mathrm{mL}$, with all these components entrapped in an alginate matrix supported by a mesh-type fabric. The strains used in our study are different, and no bacteriocin or polymer is used, but the proposed probiotic biofilm should be formed on different surfaces chosen according the purpose (an active packaging and/or a medical device). Moreover, our solution, thanks to the maintenance of a continuous metabolism, should ensure an uninterrupted and stronger activity of the active substances (mainly bacteriocins and/or other LAB-produced antimicrobial compounds such as hydrogen peroxide, carbon dioxide, diacetyl, organic acids), being the same in loco produced [37]. Similar to our study, Gomez et al. [28] used in situ biofilms formed by potential probiotic LAB strains isolated from Brazilian's foods (Lactococcus lactis VB69, L. lactis VB94, Lactobacillus sakei MBSa1, Lactobacillus curvatus MBSa3, L. lactis 368, Lactobacillus helveticus 354, Lactobacillus casei 40, and Weissela viridescens 113) to inhibit pathogenic growth: they found the total inhibition in pathogens E. coli O157:H7, L. monocytogenes and Salmonella Typhimurium biofilm formation, in 24, 48, and $72 \mathrm{~h}$ of exposure using L. lactis 368, Lactobacillus curvatus MBSa3 and Lactobacillus sakei MBSa1. For the other strains, the inhibition was time-dependent and varied according to the strain and target pathogen; for L. monocytogenes, reductions ranged from 4- to 7-log units over 24 and $48 \mathrm{~h}$, and the inhibition was observed only within the first 24-48 h, after which the pathogen was able to grow. In Salmonella Typhimurium and E. coli O157:H7 experiments, sessile cells were not detected during $24 \mathrm{~h}$ of incubation in the presence of most LAB tested; during 48 and $72 \mathrm{~h}$, reductions between 5 and $3 \log$ for E. coli O157:H7 and $4 \log$ for Salmonella Typhimurium were achieved.

Table 2. Cellular loads (Log CFU/ $/ \mathrm{cm}^{2}$ ) recovered for Listeria monocytogenes, Escherichia coli O157:H7, Staphylococcus aureus and Salmonella enterica during their sessile growth with (ACTIVE, ACT) or without (CONTROL, CNT) probiotic biofilms.

\begin{tabular}{|c|c|c|c|}
\hline \multicolumn{3}{|c|}{ L. monocytogenes } & \multirow[b]{2}{*}{ ** Biofilm Efficacy } \\
\hline Time (h) & CNT & ACT & \\
\hline 0 & $4.21 \pm 0.01^{\mathrm{A}, *}$ & $3.46 \pm 0.12^{B}$ & $0.75 \pm 0.17^{\mathrm{a}, * * *}$ \\
\hline 4 & $4.82 \pm 0.16^{\mathrm{A}}$ & $3.39 \pm 0.20^{B}$ & $1.43 \pm 0.28^{b}$ \\
\hline 24 & $4.83 \pm 0.13^{\mathrm{A}}$ & $4.10 \pm 0.10^{\mathrm{B}}$ & $0.73 \pm 0.14^{\mathrm{a}}$ \\
\hline 30 & $5.18 \pm 0.25^{\mathrm{A}}$ & $4.31 \pm 0.11^{\mathrm{B}}$ & $0.87 \pm 0.16^{\mathrm{a}}$ \\
\hline \multirow[t]{2}{*}{48} & $4.91 \pm 0.01^{\mathrm{A}}$ & $4.23 \pm 0.10^{\mathrm{B}}$ & $0.68 \pm 0.14^{\mathrm{a}}$ \\
\hline & E. coli O157:H7 & & \\
\hline Time (h) & CNT & ACT & Biofilm Efficacy \\
\hline 0 & $5.49 \pm 0.01^{\mathrm{A}}$ & $5.20 \pm 0.25^{\mathrm{A}}$ & $0.29 \pm 0.35^{\mathrm{a}}$ \\
\hline 4 & $5.43 \pm 0.14^{\mathrm{A}}$ & $4.19 \pm 0.22^{B}$ & $1.24 \pm 0.31^{b}$ \\
\hline 24 & $5.56 \pm 0.41^{\mathrm{A}}$ & $4.10 \pm 0.01^{\mathrm{B}}$ & $1.46 \pm 0.01^{b}$ \\
\hline 30 & $6.13 \pm 0.30^{\mathrm{A}}$ & $3.82 \pm 0.01^{\mathrm{B}}$ & $2.31 \pm 0.01^{c}$ \\
\hline \multirow[t]{2}{*}{48} & $6.00 \pm 0.25^{\mathrm{A}}$ & $3.80 \pm 0.20^{B}$ & $2.20 \pm 0.28^{c}$ \\
\hline & St. aureus & & \\
\hline Time (h) & CNT & ACT & Biofilm Efficacy \\
\hline 0 & $5.07 \pm 0.20^{\mathrm{A}}$ & $4.88 \pm 0.01 \mathrm{~A}$ & $0.19 \pm 0.01^{\mathrm{a}, \mathrm{b}}$ \\
\hline 4 & $5.02 \pm 0.03^{\mathrm{A}}$ & $4.70 \pm 0.33^{\mathrm{A}}$ & $0.32 \pm 0.47^{b, c}$ \\
\hline 24 & $5.57 \pm 0.14^{\mathrm{A}}$ & $4.89 \pm 0.19^{\mathrm{B}}$ & $0.68 \pm 0.27^{b, c}$ \\
\hline 30 & $5.16 \pm 0.01^{\mathrm{A}}$ & $3.86 \pm 0.22^{B}$ & $1.30 \pm 0.31^{c, d}$ \\
\hline 48 & $5.16 \pm 0.30^{\mathrm{A}}$ & $3.71 \pm 0.05^{\mathrm{B}}$ & $1.45 \pm 0.07^{\mathrm{d}}$ \\
\hline
\end{tabular}


Table 2. Cont.

\begin{tabular}{cccc}
\hline \multicolumn{3}{c}{ Salmonella enterica } \\
\hline Time (h) & CNT & ACT & Biofilm Efficacy \\
\hline 0 & $5.94 \pm 0.10^{\mathrm{A}}$ & $4.37 \pm 0.10^{\mathrm{B}}$ & $1.57 \pm 0.14^{\mathrm{a}}$ \\
\hline 4 & $5.38 \pm 0.10^{\mathrm{A}}$ & $4.47 \pm 0.16^{\mathrm{B}}$ & $0.91 \pm 0.23^{\mathrm{b}}$ \\
\hline 24 & $5.53 \pm 0.15^{\mathrm{A}}$ & $4.54 \pm 0.13^{\mathrm{B}}$ & $0.99 \pm 0.18^{\mathrm{b}}$ \\
\hline 30 & $5.35 \pm 0.23^{\mathrm{A}}$ & $4.88 \pm 0.05^{\mathrm{B}}$ & $0.47 \pm 0.07^{\mathrm{c}}$ \\
\hline 48 & $4.98 \pm 0.30^{\mathrm{A}}$ & $4.77 \pm 0.00^{\mathrm{B}}$ & $0.21 \pm 0.00^{\mathrm{c}}$
\end{tabular}

${ }^{*} \mathrm{~A}, \mathrm{~B}$, Values in the same lines with different letters are significantly different (Student's t-test) $(p<0.05) .{ }^{* *}$ Biofilm Efficacy $=$ CNT-ACT. $* * * a, b, c, d$, Values in the same columns with different letters are significantly different (one-way ANOVA and Tukey's test) $(p<0.05)$.

\subsection{Application as Potential Active Packaging}

Once ascertained the effects on pathogens growth, the research focused on the formation of the probiotic biofilm on different packaging materials, in order to individuate an innovative packaging system.

The results obtained are shown in Table 3; after only $2 \mathrm{~h}$, the probiotic biofilm was successfully formed on all tested materials, except for waxed paper. The sessile cellular load ranged from $5.77 \mathrm{log}$ $\mathrm{CFU} / \mathrm{cm}^{2}$ (grease-proof paper) to $6.94 \log \mathrm{CFU} / \mathrm{cm}^{2}$ (polyethylene). After $96 \mathrm{~h}$, polyethylene and ceramic resulted the materials on which the highest adhesion was recorded $\left(6.54 \log \mathrm{CFU} / \mathrm{cm}^{2}\right)$. In general, any surface (plastic, rubber, glass, metal, paper, cement, stainless steel or wood, or food products themselves) are vulnerable to biofilm development and each biofilm is different, thus suggesting that every situation should be analysed individually and specifically [38].

Table 3. Cellular probiotic load in sessile form $\left(\log \mathrm{CFU} / \mathrm{cm}^{2}\right)$ observed on common packaging materials used in the food industry and on ceramic.

\begin{tabular}{cccc}
\hline Materials & \multicolumn{3}{c}{ Cellular Probiotic Load in Sessile Form $(\mathbf{l o g}$ CFU/cm } \\
& $\mathbf{2}$ ) \\
\hline Polypropylene (PP) & $6.64 \pm 0.00^{\mathrm{A}}$ & $\mathbf{2 4} \mathbf{~ h}$ & $\mathbf{9 6 ~ h}$ \\
Polyvinyl chloride (PVC) & $6.54 \pm 0.14^{\mathrm{A}}$ & $5.65 \pm 0.48^{\mathrm{A}}$ & $5.88 \pm 0.23^{\mathrm{A}}$ \\
Greaseproof paper (GP) & $5.77 \pm 0.23^{\mathrm{B}}$ & $5.24 \pm 0.15^{\mathrm{B}}$ & $5.87 \pm 0.30^{\mathrm{A}}$ \\
Waxed paper (WP) & No adhesion & $4.61 \pm 0.22^{\mathrm{C}}$ & $4.53 \pm 0.06^{\mathrm{B}}$ \\
Polyethylene (PE) & $6.94 \pm 0.00^{\mathrm{A}}$ & $6.03 \pm 0.38^{\mathrm{A}}$ & $6.54 \pm 0.14^{\mathrm{D}}$ \\
Ceramic & $6.86 \pm 0.20^{\mathrm{A}}$ & $6.24 \pm 0.23^{\mathrm{A}}$ & $6.54 \pm 0.14^{\mathrm{D}}$ \\
\hline
\end{tabular}

A, B, C, Values in the same columns with different letters are significantly different (one-way ANOVA and Tukey's test) $(p<0.05)$.

Once individuated in polyethylene (PE) the material able to ensure the greatest adhesion of probiotics, in a second step, the attention was focused only on this material and it was used to test the potential for probiotic biofilms to control the growth of microorganisms in soft cheeses. The products were inoculated with L. monocytogenes (challenge test A) and Ps. fluorescens (challenge test B), wrapped in PE pellicles with pre-formed probiotic biofim, packed both in air and under vacuum, and stored at 4 and $15^{\circ} \mathrm{C}$. These model bacteria were chosen as main representatives of pathogen and spoilage bacteria naturally contaminating soft cheese $[39,40]$.

At $4{ }^{\circ} \mathrm{C}$, the cellular load of L. monocytogenes remained lower than $3 \log \mathrm{CFU} / \mathrm{g}$ for the entire observation period (28 days), regardless the presence of the probiotic biofilm or the packaging. On the other hand, at $15^{\circ} \mathrm{C}$ (simulated thermal abuse), the $\lambda$ length was always longer in samples containing probiotic biofilms (EXP samples), if compared to CNT samples (without probiotic biofilms) (Table 4): its value increased from 0.04 to 3.37 days (in air packaging, Figure 1A) and from 0.00 to 2.40 days (under vacuum, Figure 1B). The growth rate $\left(\mu_{\max }\right)$ was also influenced by the presence 
of probiotic biofilms, recording a decrease from about 0.7 to $0.4 \mathrm{Log}(\mathrm{CFU} / \mathrm{g}) /$ day, in both packaging conditions. The maximum cell load reached in the stationary phase $\left(\mathrm{A}+\mathrm{N}_{0}\right.$ ) was not influenced, reaching approximately 5.6-5.7 $\log \mathrm{CFU} / \mathrm{g}$, regardless of the presence or absence of probiotic biofilms. The cellular load of lactic bacteria (LAB) was also monitored, as well as $\mathrm{pH}$ and water activity. At $4{ }^{\circ} \mathrm{C}$, the initial LAB count was $5.75 \pm 0.18 \log \mathrm{CFU} / \mathrm{g}$ in the control samples against $8.32 \pm 0.20 \mathrm{log}$ CFU/g in the experimental cheeses; after 28 days, there were no statistically significant differences between the samples (regardless of the presence of probiotic biofilms and the type of packaging), recording cellular loads between 7 and $8 \log$ CFU/g (data not shown).

Table 4. Kinetic parameters calculated by fitting Gompertz equation to the experimental data by L. monocytogenes and Ps. fluorescens during their growth in soft cheeses with (EXP) or without (CNT) probiotic biofilms, packed in AIR o under vacuum (UV) and stored at $15^{\circ} \mathrm{C}$. (A + No) is the maximum bacterial load attained at the stationary phase, $\mu_{\max }$ is the maximal growth rate, $\lambda$ is the lag time, TRS is the sanitary risk time, ST (stability time) is the maximum acceleration of microbial growth.

\begin{tabular}{|c|c|c|c|c|}
\hline \multicolumn{5}{|c|}{ L. monocytogenes } \\
\hline & $\begin{array}{c}\mathrm{A}+\mathrm{No} \\
{[\log \mathrm{CFU} / \mathrm{g}]}\end{array}$ & $\begin{array}{c}\mu \mathrm{max} \\
{[\log (\mathrm{CFU} / \mathrm{g}) / \mathrm{day}]}\end{array}$ & $\begin{array}{c}\lambda \\
{[\text { day }]}\end{array}$ & $\begin{array}{l}\text { TRS * } \\
\text { [day] }\end{array}$ \\
\hline CNT AIR & $5.66 \pm 0.31^{\mathrm{A}}$ & $0.69 \pm 0.14^{\mathrm{A}}$ & $0.04 \pm 0.67^{\mathrm{A}}$ & 2.88 \\
\hline EXP AIR & $5.37 \pm 0.20^{\mathrm{A}}$ & $0.43 \pm 0.19^{\mathrm{A}}$ & $3.37 \pm 1.06^{\mathrm{B}}$ & 4.62 \\
\hline CNT UV & $5.94 \pm 0.85^{\mathrm{A}}$ & $0.68 \pm 0.09 \mathrm{~A}$ & $0.00 \pm 0.00^{\mathrm{A}}$ & 2.95 \\
\hline EXP UV & $5.39 \pm 0.11^{\mathrm{A}}$ & $0.47 \pm 0.09^{\mathrm{A}}$ & $2.40 \pm 0.72^{B}$ & 4.30 \\
\hline \multicolumn{5}{|c|}{ Ps. fluorescens } \\
\hline & $\begin{array}{c}\mathrm{A}+\mathrm{No} \\
{[\mathrm{Log} \mathrm{CFU} / \mathrm{g}]}\end{array}$ & $\begin{array}{c}\mu \mathrm{max} \\
{[\log (\mathrm{CFU} / \mathrm{g}) / \mathrm{day}]}\end{array}$ & $\begin{array}{c}\lambda \\
{[\text { day }]}\end{array}$ & $\begin{array}{l}\text { ST ** } \\
\text { [day] }\end{array}$ \\
\hline CNT AIR & $5.95 \pm 0.33^{\mathrm{A}}$ & $0.41 \pm 0.23^{\mathrm{A}}$ & $0.54 \pm 0.61^{\mathrm{A}}$ & 2.54 \\
\hline EXP AIR & $5.66 \pm 0.18^{\mathrm{A}}$ & $0.33 \pm 0.09^{\mathrm{A}}$ & $4.40 \pm 0.74^{\mathrm{B}}$ & 6.59 \\
\hline CNT UV & $6.00 \pm 0.19^{\mathrm{A}}$ & $0.28 \pm 0.05^{\mathrm{A}}$ & $0.00 \pm 0.50^{\mathrm{A}}$ & 3.03 \\
\hline EXP UV & $5.84 \pm 0.25^{\mathrm{A}}$ & $0.26 \pm 0.05^{\mathrm{A}}$ & $3.33 \pm 0.76^{B}$ & 6.35 \\
\hline
\end{tabular}

A, B, Values in the same columns with different letters are significantly different (one-way ANOVA and Tukey's test) $(p<0.05) .{ }^{*}$, TRS, sanitary risk time, i.e., the time required (in days) to observe an increase of $2 \log$ CFU/g in L. monocytogenes count [30]. **, stability time, i.e., the maximum acceleration of microbial growth $\left[\mathrm{dy}^{2} / \mathrm{dt}^{2}\right.$ (day)] [31].

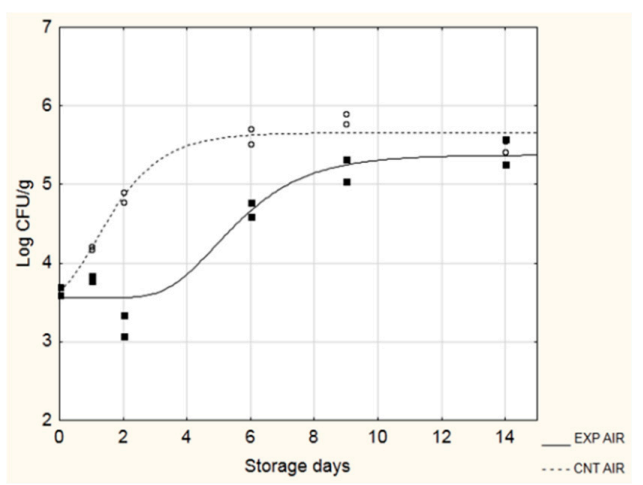

A

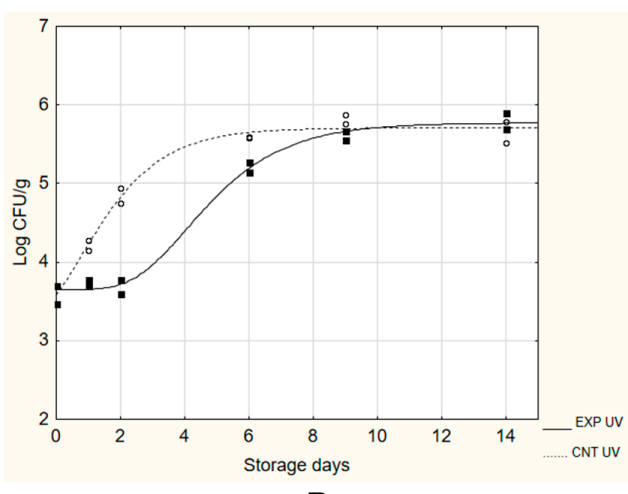

B

Figure 1. Evolution of L. monocytogenes during the challenge test at $15^{\circ} \mathrm{C}$. EXP, cheeses stored with probiotic biofilms; CNT, cheeses stored without probiotic biofilm. (A), AIR packaging; (B), under vacuum packaging (UV).

Additionally, for the $\mathrm{pH}$, no significant differences between the samples were observed; this parameter decreased from 5.31-5.39 to 4.70-4.84 at the end of storage. In all samples, the value of water activity remained constant $(0.99-1.00)$ for the entire duration of the experimentation (data not shown). Similar results were observed at $15^{\circ} \mathrm{C}$. 
During the experimentation, both at 4 and $15{ }^{\circ} \mathrm{C}$, a gradual decrease of the score from 10 to about 5.5-6 was recorded (end of storage), regardless of the presence of probiotic biofilms and the type of packaging applied, showing that the probiotic microorganisms had no impact on the sensory characteristics of cheeses; as an example, Figure 2 shows the sensorial scores for colour, odour, texture and overall acceptability of cheeses recovered during storage at $4{ }^{\circ} \mathrm{C}$.

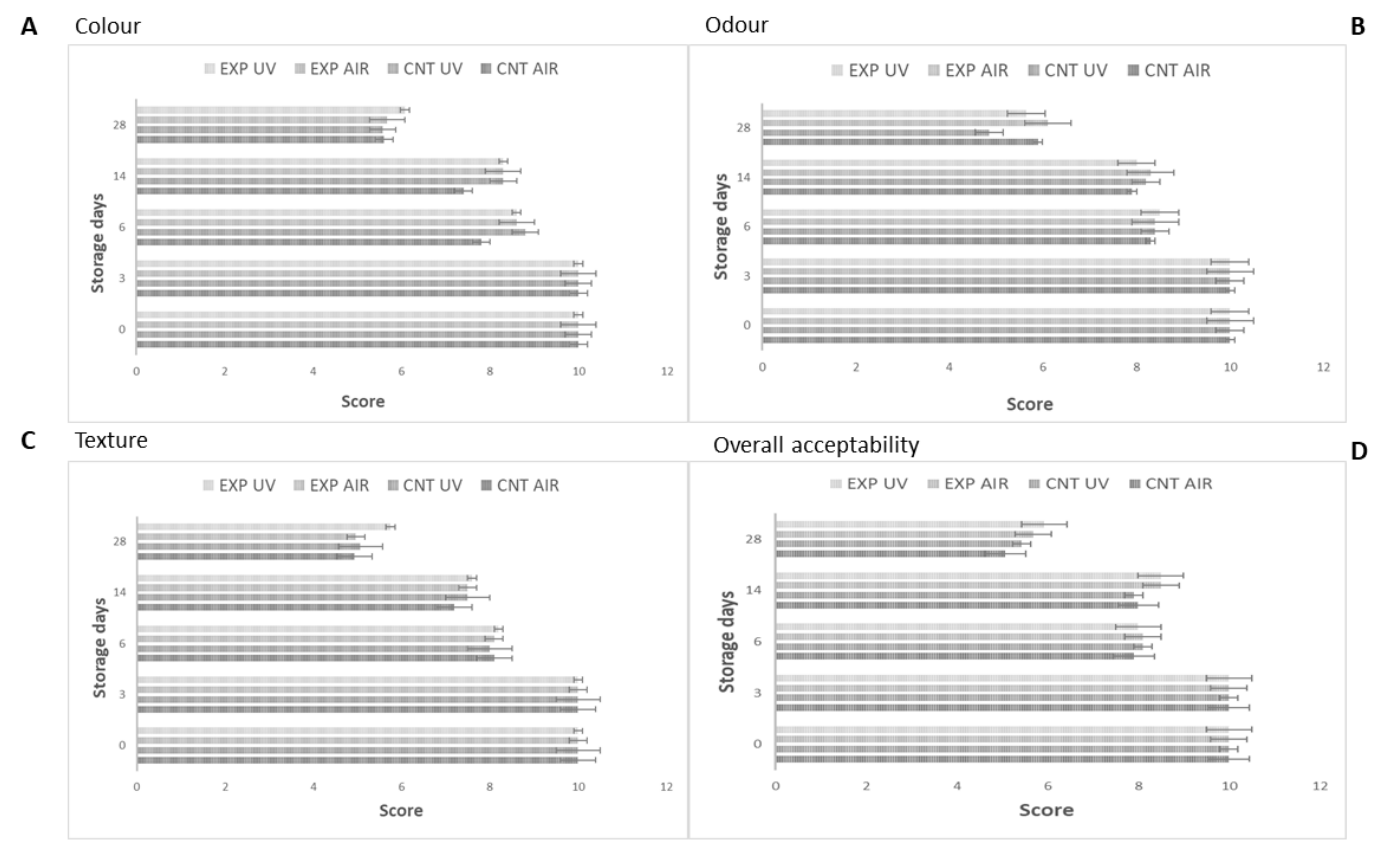

Figure 2. Sensorial scores for colour (A), odour (B), texture (C) and overall acceptability (D) of cheeses inoculated with $L$. monocytogenes stored at $4{ }^{\circ} \mathrm{C}$. Mean values \pm standard deviation. EXP, cheeses stored with probiotic biofilms; CNT, cheeses stored without probiotic biofilm.

Figure 3; Figure 4 show the evolution of Ps. fluorescens during the growth on EXP and CNT cheeses stored at 4 and $15^{\circ} \mathrm{C}$, respectively. The target microorganism was able to grow under all tested conditions, regardless of the presence of probiotic biofilms and the type of packaging. At $4{ }^{\circ} \mathrm{C}$ (Figure 3), the presence of the probiotic biofilm was able to influence the maximum cellular load reached in the stationary phase $\left(\mathrm{A}+\mathrm{N}_{0}\right)$, which was significantly lower in the EXP samples (5.59-5.72 $\log \mathrm{CFU} / \mathrm{g}$ ) compared to the CNT samples (6.36-6.39 log CFU/g). No influence was observed about the $\lambda$ length and the maximum growth rate $\left(\mu_{\max }\right)$.

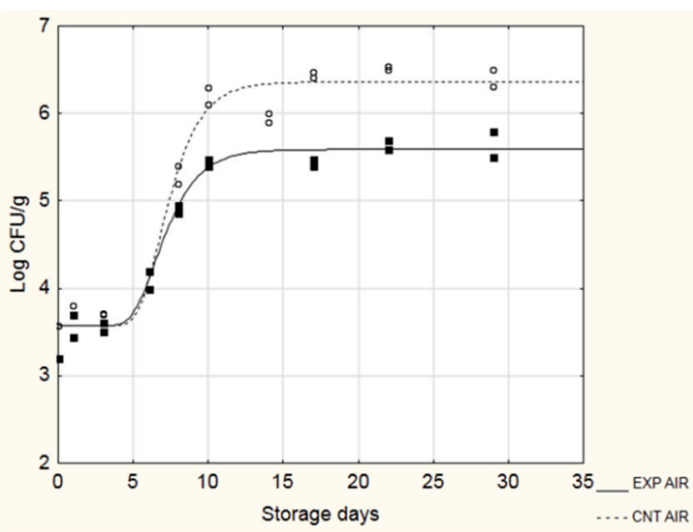

A

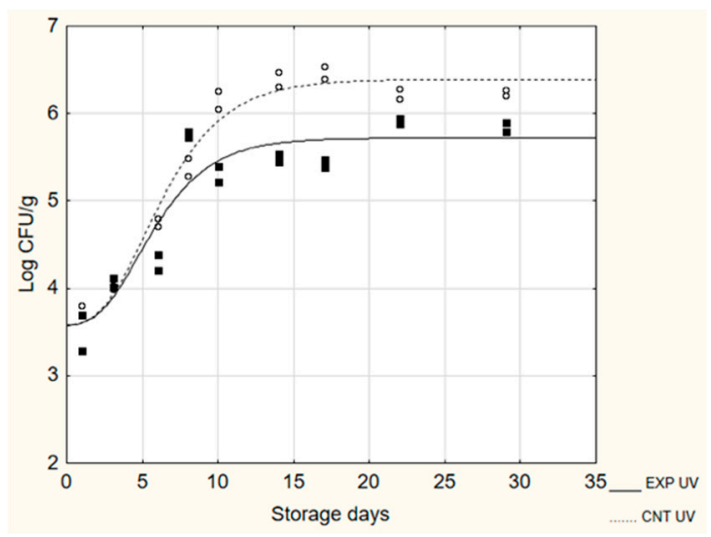

B

Figure 3. Evolution of Ps. fluorescens during the challenge test at $4{ }^{\circ} \mathrm{C}$. EXP, cheeses stored with probiotic biofilms; CNT, cheeses stored without probiotic biofilm. (A), AIR packaging; (B), under vacuum packaging (UV). 


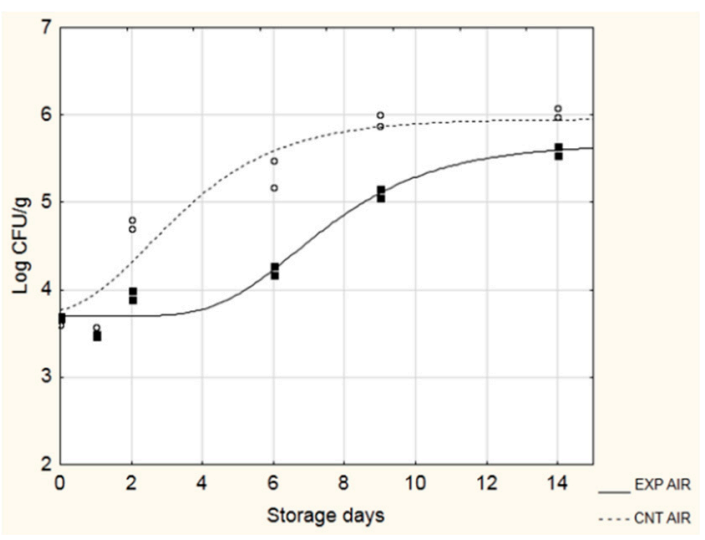

A

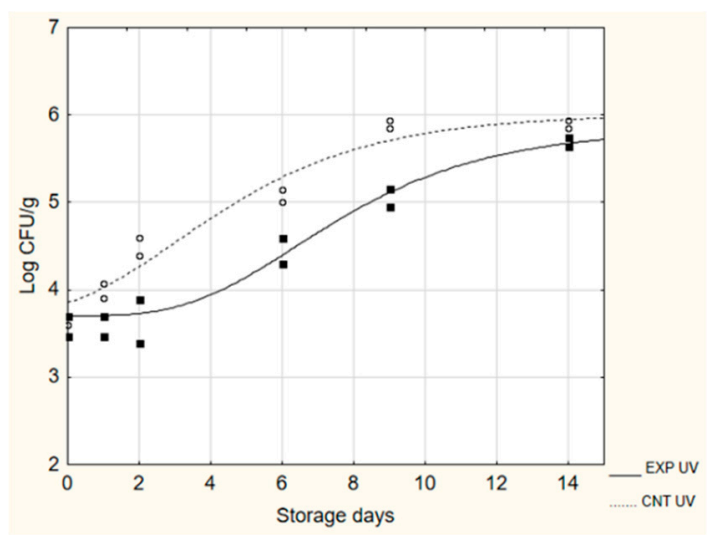

B

Figure 4. Evolution of Ps. fluorescens during the challenge test at $15^{\circ} \mathrm{C}$. EXP, cheeses stored with probiotic biofilms; CNT, cheeses stored without probiotic biofilm. (A), AIR packaging; (B), under vacuum packaging (UV).

During storage at $15{ }^{\circ} \mathrm{C}$ (Figure 4), the presence of probiotic biofilms significantly slowed the growth of the target microorganism: $\lambda$ increased from 0.54 to 4.40 days and from 0.01 to 3.30 days, in air and vacuum packaging, respectively. The maximum growth rate and the maximum cell load reached in the stationary phase were also lower in the EXP samples (probiotic biofilms) than the control samples, regardless of the packaging applied.

At both 4 and $15^{\circ} \mathrm{C}$, data on $\mathrm{LAB}, \mathrm{pH}$ and water activity were similar to those observed in the challenge test with L. monocytogenes (data not shown). Results of sensory analyses confirmed that the probiotic microorganisms had no impact on the organoleptic characteristics of cheeses (data not shown).

To highlight the effectiveness of probiotic biofilms to slow the decay of the microbiological quality of soft cheeses at $15^{\circ} \mathrm{C}$, Table 4 shows the kinetic parameters of Gompertz equation accompained by two other parameters (TRS and stability time). In a well-known study on the growth of L. monocytogenes in food, Castillejo Rodriguez et al. [30] have proposed the sanitary risk time (TRS) for this pathogen as the time required (in days) to observe an increase of $2 \log \mathrm{CFU} / \mathrm{g}$ in its count, considering that, under normal conditions, such a microorganism is present in foods in very low concentrations. As can be seen, for soft cheeses wrapped in probiotic biofilms and packaged both in air and under vacuum, the TRS was equal to 4.40-4.60 days; on the contrary, the same methods of packaging, applied to the control samples, allowed L. monocytogenes to reach risky cell counts in shorter times (2.88-2.95 days) $(p<0.05)$.

For the tests conducted with Ps. fluorescens at $15^{\circ} \mathrm{C}$, Table 4 also shows the stability time [31,41] which represents the maximum acceleration of microbial growth and indicates how long the product remains stable: after this time, an irreversible decay of the product begins. This parameter is generally used as an alternative to shelf life: the underlying principle implies that microbial degradation has to show a rate of the same order of magnitude as at the shelf life zero time. This condition is no longer met when microbial growth attains its maximum acceleration, because beyond such a threshold the system undergoes very fast changes with a rapid loss of the generally accepted safety or quality requirements. This principle seems more reliable than the current practice that defines food stability according to the ratio between attained and starting microbial population levels. The stability time increased by more than 3 and 4 days, in vacuum packaging and in air, respectively, highlighting the effectiveness of biofilms in slowing the decay of the microbiological quality of soft cheese.

Regarding the inhibitory effect of LAB against L. monocytogenes, some studies have already explored the possibility to use a preformed biofilm to inhibit the pathogen growth $[15,16,18,42]$. Namely, Guerrieri et al. [15] showed the potential of a Lactobacillus plantarum strain to reduce the pathogen growth over a 10-day period (about 4-log reduction). Mariani et al. [42] used the native 
biofilm microflora of wooden cheese ripening shelves to achieve a 1- to 2-log reduction over a 12-day period. In previous studies, we have evaluated the use of LAB biofilms as a means to control the growth of L. monocytogenes in soft cheeses [16] and in laboratory media [18], finding that sessile LAB biofilms were able to delay the growth of L. monocytogenes. An anti-listerial activity was also observed by Léonard et al. [43] during their studies on biopolymeric matrices based on alginate and alginate-caseinate (an aqueous two-phase system) entrapping Lactococcus lactis subsp. lactis LAB3 cells and by Barbosa et al. [44] who entrapped Lactobacillus curvatus in calcium alginate: the effect against the pathogen was correlated to antimicrobial metabolites of proteinaceous nature.

\section{Conclusions}

This study has explored whether probiotic bacteria able to adhere on different surfaces (i.e., packaging materials, ceramic, plastic, paper, polymers, etc.) could be used as new biotechnological solutions for industrial applications by biocontrolling the growth of pathogenic and spoilage bacteria.

The results obtained have shown the studied biofilm was able to delay the growth of some pathogenic targets; in fact, cellular pathogenic loads were always lower in presence of probiotic biofilm compared to its absence. For E. coli O157:H7, a significant cell load decrease (>1-2 logarithmic cycles) was recorded, whereas for L. monocytogenes, St. aureus and S. enterica, cell load reductions ranged from 0.5 to 1.5 logarithmic cycles.

After only $2 \mathrm{~h}$, the probiotic biofilm was successfully formed on polypropylene, polyvinyl chloride, greaseproof paper, polyethylene and ceramic, with polyethylene and ceramic resultingly being the material with the highest adhesion $\left(6.54 \log \mathrm{CFU} / \mathrm{cm}^{2}\right)$. When testing as a tool to control the growth of microorganisms in soft cheeses, the results highlighted the effectiveness of biofilms in slowing the growth of L. monocytogenes by prolonging their microbiological stability at $15^{\circ} \mathrm{C}$ by more than 3 and 4 days.

The results obtained suggest that the developed probiotic lactic acid bacteria biofilms have a good potential to be used as biocontrol agents against pathogenic and food spoilage bacteria through exclusion mechanisms: however, the mechanisms responsible for the inhibition have to be deeply investigated.

\section{Patents}

B.S., A.L. and M.R.C. applied for a patent covering the use of probiotic biofilms as a mean to control pathogens growth: Method for producing microbial probiotic biofilms and uses thereof (WO2017203440). International Application No.: PCT/IB2017/053055. National Application No.: P1287IT.

Author Contributions: Conceptualization, B.S, A.L. and M.R.C.; methodology, B.S. and M.R.C.; investigation, B.S.; resources, M.R.C.; writing-original draft preparation, B.S, A.L.and M.R.C.; writing—review and editing, B.S, A.L., V.R. and M.R.C. All authors have read and agreed to the published version of the manuscript.

Funding: This research received no external funding.

Conflicts of Interest: The authors applied for a patent covering the use of probiotic biofilms as a mean to control pathogens growth.

\section{References}

1. Ouwehand, A.C.; Salminen, S.; Isolauri, E. Probiotics: An overview of beneficial effects. Antonie Van Leeuwenhoek 2002, 82, 279-289. [CrossRef]

2. Hill, C.; Guarner, F.; Reid, G.; Gibson, G.R.; Merenstein, D.J.; Pot, B.; Morelli, L.; Canani, R.B.; Flint, H.J.; Salminen, S.; et al. Expert consensus document: The international scientific association for probiotics and prebiotics consensus statement on the scope and appropriate use of the term probiotic. Nat. Rev. Gastroenterol. Hepato. 2014, 11, 506-514. [CrossRef]

3. Charalampopoulos, D.; Rastall, R.A. Prebiotics and Probiotics Science and Technology; Springer: New York, NY, USA, 2009; p. 1262. 
4. Corbo, M.R.; Speranza, B.; Sinigaglia, M. Microbial biofilms in the food industry: only negative implications? In Biofilms: Formation, Development and Properties; Bailey, W.C., Ed.; Nova Science Publishers: New York, NY, USA, 2009; pp. 585-594.

5. Carducci, A.; Verani, M.; Lombardi, R.; Casini, B.; Privitera, G. Environmental survey to assess viral contamination of air and surfaces in hospital settings. J. Hosp. Infect. 2011, 77, 242-247. [CrossRef] [PubMed]

6. Eschenbach, D.A.; Patton, D.L.; Hooton, T.M.; Meier, A.S.; Stapleton, A.; Aura, J.; Agnew, K. Effects of vaginal intercourse with and without a condom on vaginal flora and vaginal epithelium. J. Infect. Dis. 2001, 183, 913-918. [CrossRef] [PubMed]

7. Vuotto, C.; Barbanti, F.; Mastrantonio, P.; Donelli, G. Lactobacillus brevis CD2 inhibits Prevotella melaninogenica biofilm. Oral. Dis. 2014, 20, 668-674. [CrossRef] [PubMed]

8. Ma, L.; Lv, Z.; Su, J.; Wang, J.; Yan, D.; Wei, J.; Pei, S. Consistent Condom Use Increases the Colonization of Lactobacillus crispatus in the Vagina. PLoS ONE 2013, 8, e70716. [CrossRef] [PubMed]

9. Leccese Terraf, M.C.; Juarez Tomas, M.S.; Nader-Macias, M.E.F.; Silva, C. Screening of biofilm formation by beneficial vaginal lactobacilli and influence of culture media components. J. Appl. Microbiol. 2012, 113, 1517-1529. [CrossRef] [PubMed]

10. Salo, S.; Ehavald, H.; Raaska, L.; Vokk, R.; Wirtanen, G. Microbial surveys in Estonian dairies. LWT Food Sci. Technol. 2006, 39, 460-471. [CrossRef]

11. Sharma, M.; Anand, S.K. Biofilms evaluation as an essential component of HACCP for food/dairy processing industry e a case. Food Control 2002, 13, 469-477. [CrossRef]

12. Waak, E.; Tham, W.; Danielsson-Tham, M.L. Prevalence and fingerprinting of Listeria monocytogenes strains isolated from raw whole milk in farm bulk tanks and in dairy plant receiving tanks. Appl. Env. Microbiol. 2002, 68, 3366-3370. [CrossRef]

13. Speranza, B.; Corbo, M.R. The impact of biofilms on food spoilage. In The Microbiological Quality of Food: Foodborne Spoilers; Bevilacqua, A., Corbo, M.R., Sinigaglia, M., Eds.; Elsevier: Oxford, UK, 2017; pp. $259-282$.

14. Guillier, L.; Stahl, V.; Hezard, B.; Notz, E.; Briandet, R. Modelling the competitive growth between Listeria monocytogenes and biofilm microflora of smear cheese wooden shelves. Int. J. Food Microbiol. 2008, 128, 51-57. [CrossRef]

15. Guerrieri, E.; de Niederhäusern, S.; Messi, P.; Sabia, C.; Iseppi, R.; Anacarso, I.; Bondi, M. Use of lactic acid bacteria (LAB) biofilms for the control of Listeria monocytogenes in a small-scale model. Food Control 2009, 20, 861-865. [CrossRef]

16. Speranza, B.; Sinigaglia, M.; Corbo, M.R. Non starter lactic acid bacteria biofilms: A means to control the growth of Listeria monocytogenes in soft cheese. Food Control 2009, 20, 1063-1067. [CrossRef]

17. Vandini, A.; Temmerman, R.; Frabetti, A.; Caselli, E.; Antonioli, P.; Balboni, P.G.; Platano, D.; Branchini, A.; Mazzacane, S. Hard Surface Biocontrol in Hospitals Using Microbial-Based Cleaning Products. PLoS ONE 2014, 9, e108598. [CrossRef]

18. Speranza, B.; Liso, A.; Corbo, M.R. Use of design of experiments to optimize the production of microbial probiotic biofilms. PeerJ 2018, 6, e4826. [CrossRef]

19. Method for Producing Microbial Probiotic Biofilms and Uses thereof WO2017203440. Available online: https://patents.google.com/patent/WO2017203440A1/en (accessed on 25 November 2019).

20. Gudiña, E.J.; Teixeira, J.A.; Rodrigues, L.R. Isolation and functional characterization of a biosurfactant produced by Lactobacillus paracasei. Colloid Surf. B 2010, 76, 298-304. [CrossRef]

21. Jones, S.E.; Versalovic, J. Probiotic Lactobacillus reuteri biofilms produce antimicrobial and anti-inflammatory factors. BMC Microbiol 2009, 9, 35. [CrossRef]

22. Rodrigues, L.; Banat, I.M.; Teixeira, J.; Oliveira, R. Biosurfactants: potential applications in medicine. J. Antimicrob. Chemoth. 2006, 57, 609-618. [CrossRef]

23. Rodrigues, L.; Banat, I.M.; Teixeira, J.; Oliveira, R. Strategies for the prevention of microbial biofilm formation on silicone rubber voice prostheses. J. Biomed Mater Res. B 2007, 81, 358-370. [CrossRef]

24. Rodrigues, L.; van der Mei, H.C.; Banat, I.M.; Teixeira, J.; Oliveira, R. Inhibition of microbial adhesion to silicone rubber treated with biosurfactant from Streptococcus thermophilus A. FEMS Immunol. Med. Microbiol. 2006, 46, 107-112. [CrossRef]

25. Rodrigues, L.; van der Mei, H.C.; Teixeira, J.; Oliveira, R. Influence of biosurfactants from probiotic bacteria on formation of biofilms on voice prostheses. Appl. Env. Microbiol. 2004, 70, 4408-4410. [CrossRef] 
26. Rodrigues, L.R.; Banat, I.M.; van der Mei, H.C.; Teixeira, J.A.; Oliveira, R. Interference in adhesion of bacteria and yeasts isolated from explanted voice prostheses to silicone rubber by rhamnolipid biosurfactants. J. Appl. Microbiol. 2006, 100, 470-480. [CrossRef]

27. Rodrigues, L.R.; Teixeira, J.A.; van der Mei, H.C.; Oliveira, R. Physicochemical and functional characterization of a biosurfactant produced by Lactococcus lactis 53. Colloid Surf. B 2006, 49, 79-86. [CrossRef]

28. Gómez, N.C.; Ramiro, J.M.P.; Quecan, B.X.V.; de Melo Franco, B.D.G. Use of potential probiotic lactic acid bacteria (LAB) biofilms for the control of Listeria monocytogenes, Salmonella Typhimurium, and Escherichia coli O157: H7 biofilms formation. Front. Microbiol. 2016, 7, 863. [CrossRef]

29. Mandakhalikar, K.D.; Rahmat, J.N.; Chiong, E.; Neoh, K.G.; Shen, L.; Tambyah, P.A. Extraction and quantification of biofilm bacteria: Method optimized for urinary catheters. Sci. Rep. 2018, 8, 8069. [CrossRef]

30. Zwietering, M.H.; Jogenburger, I.; Rombouts, F.M.; Van't Riet, K. Modelling of the bacterial growth curve. Appl. Environ. Microbiol. 1990, 56, 1975-1981. [CrossRef]

31. Castillejo Rodrìguez, A.M.; Barco Alcalà, E.; Garcia Gimeno, R.M.; Zurera Cosano, G. Growth modelling of Listeria monocytogenes in packaged fresh green asparagus. Food Microbiol. 2000, 17, 421-427. [CrossRef]

32. Riva, M.; Franzetti, L.; Galli, A. Microbiological quality and shelf life modeling of ready-to-eat cicorino. J. Food Prot. 2001, 64, 228-234. [CrossRef]

33. Abdelhamid, A.G.; Esaam, A.; Hazaa, M.M. Cell free preparations of probiotics exerted antibacterial and antibiofilm activities against multidrug resistant E. coli. Saudi Pharm. J. 2018, 26, 603-607. [CrossRef]

34. Kaboosi, H. Antibacterial effects of probiotics isolated from yoghurts against some common bacterial pathogens. Afr. J. Microbiol. Res. 2011, 5, 4363-4367. [CrossRef]

35. Tejero-Sariñena, S.; Barlow, J.; Costabile, A.; Gibson, G.R.; Rowland, I. Antipathogenic activity of probiotics against Salmonella Typhimurium and Clostridium difficile in anaerobic batch culture systems: is it due to synergies in probiotic mixtures or the specificity of single strains? Anaerobe 2013, 24, 60-65. [CrossRef]

36. Barbosa, M.S.; Todorov, S.D.; Jurkiewicz, C.H.; Franco, B.D.G.M. Bacteriocin production by Lactobacillus curvatus MBSa2 entrapped in calcium alginate during ripening of salami for control of Listeria monocytogenes. Food Control 2015, 47, 147-153. [CrossRef]

37. Gálvez, A.; Abriouel, H.; Ben Omar, N. Bacteriocin-based strategies for food biopreservation. Int. J. Food Microbiol. 2007, 120, 51-70. [CrossRef]

38. Srey, S.; Jahid, I.K.; Ha, S. Biofilm formation in food industries: a food safety concern. Food Control 2013, 31, 572-585. [CrossRef]

39. De Buyser, M.L.; Dufour, B.; Maire, M.; Lafarge, V. Implication of milk and milk products in food-borne diseases in France and different industrialized countries. Int. J. Food Microbiol. 2001, 67, 1-17. [CrossRef]

40. Martin, N.H.; Murphy, S.C.; Ralyea, R.; Boor, K.J. When cheese gets the blues: Pseudomonas fluorescens as the causative agent of cheese spoilage. J. Dairy Sci. 2011, 94, 3176-3183. [CrossRef]

41. Corbo, M.R.; Altieri, C.; D’Amato, D.; Campaniello, D.; Del Nobile, M.A.; Sinigaglia, M. Effect of temperature on shelf life and microbial population of lightly processed cactus pear fruit. Postharvest Biol. Technol. 2004, 31, 93-104. [CrossRef]

42. Mariani, C.; Oulahal, N.; Chamba, J.F.; Dubois-Brissonnet, F.; Notz, E.; Briandet, R. Inhibition of Listeria monocytogenes by resident biofilms present on wooden shelves used for cheese ripening. Food Control 2011, 22, 1357-1362. [CrossRef]

43. Léonard, L.; Degraeve, P.; Gharsallaoui, A.; Saurel, R.; Oulahal, N. Design of biopolymeric matrices entrapping bioprotective lactic acid bacteria to control Listeria monocytogenes growth: Comparison of alginate and alginate-caseinate matrices entrapping Lactococcus lactis subsp. lactis cells. Food Control 2014, 37, 200-209. [CrossRef]

44. Schöbitz, R.; González, C.; Villarreal, K.; Horzella, M.; Nahuelquín, Y.; Fuentes, R. A biocontroller to eliminate Listeria monocytogenes from the food processing environment. Food Control 2014, 36, 217-223. [CrossRef]

(C) 2020 by the authors. Licensee MDPI, Basel, Switzerland. This article is an open access article distributed under the terms and conditions of the Creative Commons Attribution (CC BY) license (http://creativecommons.org/licenses/by/4.0/). 